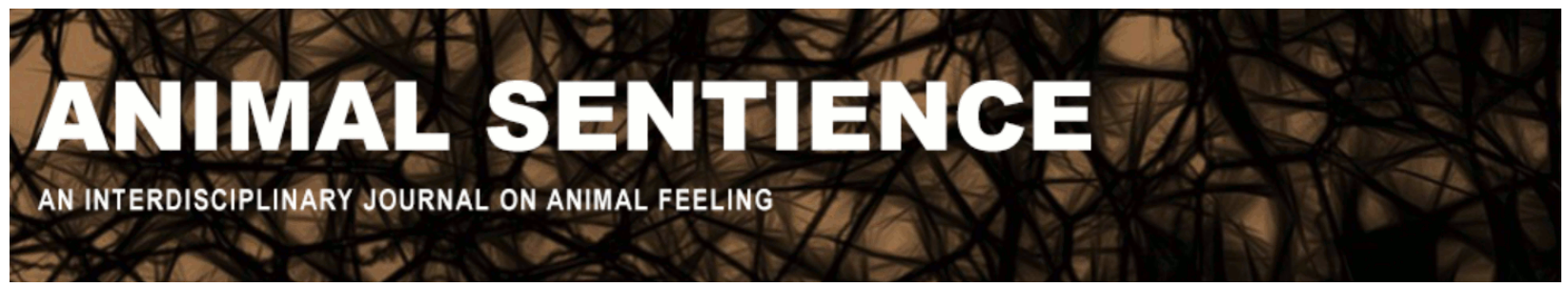

Benz-Schwarzburg, Judith (2016) What do we owe animals as persons?. Animal Sentience 10(9)

DOI: $10.51291 / 2377-7478.1154$

Date of submission: 2016-08-26

Date of acceptance: 2016-08-29

(c)

This article has appeared in the journal Animal

Sentience, a peer-reviewed journal on animal

cognition and feeling. It has been made open access,

free for all, by WellBeing International and deposited

in the WBI Studies Repository. For more information,

please contact

wbisr-info@wellbeingintl.org.

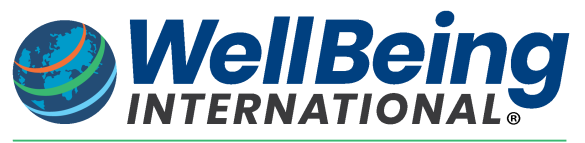

SOLUTIONS FOR PEOPLE, ANIMALS AND ENVIRONMENT 


\title{
What do we owe animals as persons?
}

Commentary on Rowlands on Animal Personhood

\author{
Judith Benz-Schwarzburg \\ Unit of Ethics and Human-Animal Studies, Messerli Research Institute, Vienna
}

\begin{abstract}
Rowlands (2016) concentrates strictly on the metaphysical concept of person, but his notion of animal personhood bears a moral dimension (Monsó, 2016). His definition of pre-reflective self-awareness has a focus on sentience and on the lived body of a person as well as on her implicit awareness of her own goals. Interestingly, these also play a key role in animal welfare science, as well as in animal rights theories that value the interests of animals. Thus, Rowlands's concept shows connectivity with both major fields of animal ethics. His metaphysical arguments might indeed contain a strong answer to the question of what we owe animals as persons.
\end{abstract}

Keywords: person, animal welfare, animal rights, self-awareness

Judith Benz-Schwarzburg is Senior Researcher at the Unit for Ethics and Human-Animal Studies of the University of Veterinary Medicine, Vienna, the University of Vienna and the Medical University of Vienna. Her work focuses on sociocognitive abilities in animals and their ethical relevance (for culture, language, theory of mind, and morality in animals). https://www.vetmeduni.ac.at/en/messerli/science/ethik/st aff/judith-benz-schwarzburg/

Rowlands's (2016) concept of persons as pre-reflectively self-aware beings seems to be open to a much wider range of species than have been acknowledged as potential persons so far. Rowlands is only interested in the metaphysical notion of person, but, as Monsó (2016) points out, his argument has a moral dimension: it establishes animals as moral patients who are equipped with pre-reflective self-awareness, consciousness and sentience. What follows from the idea that such moral patients are to be morally considered in virtue of their personhood? Clearly, this deserves specification. Furthermore, the successful transfer of Rowlands's metaphysical endeavour to the "real world" of applied animal ethics will depend on the ability of his concept to connect with theories in applied animal ethics and animal welfare. Thus, I will show two dimensions, (1) and (2), where his concept opens up for such connections.

Rowlands establishes a model of self-awareness that links self-awareness and consciousness with a person's experiences, her goals and her awareness of her own body. Pain perception is a perfect example of a conscious experience that comes with a prereflective awareness of one's own body: "To feel pain is to be in pain, and vice versa. [...] knowing that I am in pain is part of what it is to be in pain rather than a separate act that has my pain as its intentional object" (Rowlands, 2016, p. 6).

There are (at least) two dimensions in this concept of self-awareness that are also at the centre of debates in animal ethics. The first refers to the role of conscious pain perception (1), the second to the importance of an individual's goals (2). 
1. Conscious Pain Perception. Most ethical theories grant special value to sentience: There is a clear connection between sentience - or, alternatively, the harm we can do to an animal - and any treatment that does not respect the animal's bodily integrity. Beings who are self-aware of their pleasure and pain, who experience both as states that matter to them, are entitled to what is called individual welfare. Moreover, sentience, welfare or vulnerability, and consciousness all come together in our everyday understanding of persons and how we should treat them:

\footnotetext{
"Because we can experience pain so intensely and because we value our ability to choose our own actions so deeply, we neither accept, nor minimize it when other people hurt, coerce, threaten or manipulate us. We object to such actions so strongly that we label them not just 'inconvenient' or 'unpleasant', but as 'wrong'. Ethics - our labelling actions as 'right' or 'wrong' - is grounded in the idea that the type of consciousness that we have gives us special capacities and vulnerabilities. When we label something as 'wrong', then, we're saying that it crosses the line with regard to not respecting some fundamental feature that makes us human." (White, 2007, p. 155, emphasis by the author)
}

If we can replace "makes us human" here with "makes us persons" (which we probably can do, because we usually presuppose that all humans are persons), and if the kind of consciousness that makes us persons is in fact pre-reflective self-awareness, then being a pre-reflectively self-aware person means being prone to special vulnerabilities.

2. Importance of Individual's Goals. Second, most ethical theories demand respect for an individual's goals, which means that individuals' preferences and interests matter. This can be either an indirect claim (2a), which takes the route of understanding harm and welfare as morally relevant concepts, or a direct claim (2b), derived from an animal rights theory.

According to (2a), harm is inflicted if animals are treated in ways that do not allow them to follow (and meet) their goals and interests, or, in the language of veterinary medicine, their ethological or behavioural needs (Hughes \& Duncan, 1988; Jensen \& Toate 1993). The kind of harm we are talking about here points to the possibility of psychological suffering in animals, which has long been underestimated. It is noteworthy, though, that the welfare-based claim to respect an animal's goals and interests can still be negotiated via a utilitarian weighting procedure - that is, it need not be something that has a strong standing should the benefits on the human side outweigh the costs on the animal's side.

According to (2b), however, an individual's goals or interests are a considerably more important and value-laden matter to begin with. If animals are included in the community of beings where every person holds strong, inviolable rights, then killing, hurting, or confining them is not a question of weighing costs and benefits but morally wrong in principle. It is this strong notion of personhood that we usually mean when we talk about the human right not to be killed, tortured or imprisoned. Understood like this, personhood is the strongest moral status we have so far debated for animals. Applied to humans and animals it has an unprecedented power to elucidate as well as to guide.

Thus, the language of personhood can go very much beyond animal welfare claims and points clearly to animal rights. It even points to specific kinds of animal rights that are similar or even identical to basic human rights. Three rights for animal persons have been highlighted in the literature: the right to life, the right not to be tortured and the right to freedom (see e.g. the Great Ape Project as it was put forward by Cavalieri \& Singer, 1993). Whereas the second right (the right not to be tortured) is surely grounded in the animal's conscious experience of pain, the first and third (the right to life and the right to freedom) go 
beyond a sheer welfare logic. If all pre-reflectively self-aware animals are indeed persons, we have to discuss whether and to what extent they should be afforded the rights that have been connected with an orthodox understanding of personhood and have hitherto been reserved for humans alone.

Rowlands (2016) is aware that he is opening the community of persons to many more beings than "the (self-appointed) crème of the animal kingdom: humans above a certain age, and possibly (although, here, one might have to hold one's nose) other hominids and cetaceans" (p. 15). He deliberately integrates his concept of pre-reflective self-awareness with a concept of personhood. This surely means something. It means, at the very least, that his theory confronts us with some very important questions: What special capacities, and above all, vulnerabilities does pre-reflective self-awareness give animals? What do we owe them because of this? And how strongly do we owe it them?

The possible rights we owe nonhuman persons, if we stick to the three I named in (2b), come with consequences for virtually all areas where we use and kill animals, be it meat consumption, animal experimentation, or animal husbandry in zoos and aquaria. Thus, the metaphysical question about the person quickly transforms into an applied question about how we should treat nonhuman persons. Rowlands's theories, which are carefully crafted and rather complicated, show that answering the metaphysical question is already a major conceptual endeavour. But in view of its societal and political relevance, answering the moral question will surely be the even bigger challenge.

\section{References}

Cavalieri, P. \& Singer, P. (1993). The great ape project: equality beyond humanity. St. Martin's Griffin, New York.

Hughes, B. O. \& Duncan, I. J. H. (1988). The notion of ethological 'need', models of motivation and animal welfare. Animal Behaviour 36 (6): 1696-1707.

Jensen P. \& Toates, F. M. (1993). Who needs 'behavioural needs'? Motivational aspects of the needs of animals. Applied Animal Behaviour Science 37 (2): 161-181.

Monsó, S. (2016). The moral dimension of pre-reflective self-awareness: Commentary on Rowlands on Animal personhood. Animal Sentience 2016.121.

Rowlands, M. (2016). Are animals persons? Animal Sentience 2016.101.

White, T. (2007). In defense of dolphins: the new moral frontier. Malden (MA); Oxford; Victoria: Blackwell Publishing. 